\title{
Echocardiographic assessment of ejection fraction in left ventricular hypertrophy
}

\author{
B Wandt, L Bojö, K Tolagen, B Wranne
}

\begin{abstract}
Objective-To investigate the value of Simpson's rule, Teichholz's formula, and recording of mitral ring motion in assessing left ventricular ejection fraction (EF) in patients with left ventricular hypertrophy.

Design-Left ventricular ejection fraction calculated by Simpson's rule and by Techholz's formula and estimated by mitral ring motion was compared with values obtained by radionuclide angiography.

Setting-Secondary referral centre.

Patients-16 patients with left ventricular hypertrophy and a clinical diagnosis of hypertrophic cardiomyopathy or hypertension.

Results-Calculation by Teichholz's formula overestimated left ventricular ejection fraction by $10 \% \quad(p=0.002)$ and estimation based on mitral ring motionthat is, long axis measurementsunderestimated ejection fraction by $19 \%$ $(p=0.002)$, without significant correlation between ring motion and ejection fraction. There was no significant difference between mean values of ejection fraction calculated by Simpson's rule and measured by the reference method, but a considerable scatter about the regression line with a standard error of the estimate of $9.3 \mathrm{EF} \%$. Conclusions-In patients with left ventricular hypertrophy the ejection fraction, calculated by Teichholz's formula or Simpson's rule, is a poor measure of left ventricular function. When mitral ring motion is used for the assessment in these patients the function should be expressed in ways other than by the ejection fraction. (Heart 1999;82:192-198)
\end{abstract}

Keywords: left ventricular hypertrophy; ejection fraction; mitral ring motion; atrioventricular plane displacement

Left ventricular systole involves a shortening in the long axis of the ventricle, a reduction of the inner diameter in the short axis, and a slight twisting motion about the long axis. ${ }^{1-4}$ During the shortening in the long axis the apex is relatively stationary, while the mitral ring moves towards the apex of the heart. ${ }^{15-15}$

The short axis systolic diameter reduction, the long axis shortening, and a combination of these have been used for calculation of left ventricular ejection fraction. In $\mathrm{M}$ mode echocardiography the most commonly used equation for calculation of ejection fraction, based on short axis diameter reduction, is Teichholz's formula ${ }^{16}$ which has been used since the end of the 1970s. This equation is based on the cube formula with correction factors for the increasingly spherical shape of the ventricle with increasing dilatation. The relation between the blood volume of the ventricle $(\mathrm{V})$ and the short axis inner diameter (D) according to the formula is:

$$
V=\frac{7 \times D^{3}}{2.4+D}
$$

During recent years estimation of ejection fraction based on mitral ring motion has gained ground. Several studies have shown that the relation between mitral ring motion (MRM) and ejection fraction (EF), assessed by left ventricular angiography or radionuclide angiography, is approximately $\mathrm{EF}(\%)=\mathrm{MRM}(\mathrm{mm})$ $\times 5$ in patients with coronary artery disease, ${ }^{17}$ in patients with acute myocardial infarction, ${ }^{18}$ in patients with dilated cardiomyopathy, ${ }^{11}$ and in consecutive patients referred for both echocardiography and radionuclide angiography (categories of patients not mentioned). ${ }^{19}$ Reference values for mitral ring motion have also recently been presented. ${ }^{20}$ However, there are few data on the validity of calculating the ejection fraction from dimension changes in the short and long axis in patients with left ventricular hypertrophy, defined as increased wall thickness. We undertook the present study to analyse whether the equations mentioned above can also be used to calculate the ejection fraction in patients with left ventricular hypertrophy. We had the clinical impression that these patients had reduced mitral ring motion compared with other patients, even when left ventricular function looked good on the short axis.

Another aim was to evaluate the usefulness of Simpson's rule, the most commonly used two dimensional echocardiographic method, in the same patient group.

Radionuclide angiography was used as the gold standard.

\section{Methods}

STUDY POPULATION

Seven patients with a clinical diagnosis of hypertrophic cardiomyopathy, aged 23 to 52 years (mean 38), and nine patients with clinical diagnosis hypertension, aged 42 to 72 (mean 57), were included in the study after giving informed consent. All had a mean thickness of the septum and posterior wall of $\geqslant 14 \mathrm{~mm}$. The hypertensive patients were consecutively selected from the hypertension clinic at the hospital and the patients with hypertrophic cardiomyopathy were selected from the patient database of the department of medicine. 
Table 1 Clinical data

\begin{tabular}{lllllll}
\hline Patient & Sex & $\begin{array}{l}\text { Age } \\
\text { (years) }\end{array}$ & Diagnosis & History & $\begin{array}{l}\text { *Systolic gradient } \\
(\text { mm Hg) }\end{array}$ & Drugs influencing heart action \\
\hline 1 & M & 26 & HCMP & - & $<10$ & Metoprolol \\
2 & M & 23 & HCMP & - & $<10$ & Metoprolol \\
3 & F & 30 & HCMP & - & $<10$ & Sotalol, verapamil \\
4 & M & 52 & HCMP & - & $<10$ & Sotalol, lisinopril \\
5 & F & 42 & HT & - & $<10$ & Atenolol, nifedipine, lisinopril \\
6 & M & 63 & HT & A & $<10$ & Felodipine, metoprolol \\
7 & M & 51 & HT & A, U & $<10$ & Amlodipine, doxazosine \\
8 & M & 58 & HT & - & $<10$ & Metoprolol, diltiazem \\
9 & F & 47 & HCMP & - & 61 & Metoprolol \\
10 & F & 63 & HT & D & $<10$ & Enalapril, flecainide, digoxin \\
11 & M & 72 & HT & A & 13 & Captopril, atenolol \\
12 & M & 67 & HT & A & $<10$ & Doxazosin, diltiazem, atenolol \\
13 & F & 51 & HT & A & $<10$ & Atalol \\
14 & F & 43 & HCMP & - & $<10$ & Atenolol \\
15 & F & 46 & HCMP & - & 11 & $<10$ \\
16 & M & 48 & HT & - & & \\
\hline
\end{tabular}

^Subvalvar maximum, by Doppler.

A, angina pectoris; D, diabetes; U, uraemia, HCMP, hypertrophic cardiomyopathy; HT, hypertension.

Patients with atrial fibrillation, pacemaker treatment, a history of myocardial infarction, or a history of cardiac surgery were excluded. Details of the patients are given in table 1 .

For the echocardiographic studies, age matched healthy controls were recruited; these were mainly hospital employees and relatives, seven women and nine men, aged 24 to 71 years (mean 48). They had no history of cardiac disease, normal blood pressure, normal findings on physical examination, and a normal resting ECG. All subjects over 40 also performed an exercise test without signs of heart disease.

In the reproducibility study, 10 consecutive patients from the hypertrophy group were included.

The protocol was approved by the local ethics committee. The number of subjects in the study was restricted, according to guidelines for studies where nuclear radiation is involved, and according to the rules of the local ethics and isotope committees.

\section{ECHOCARDIOGRAPHIC EXAMINATION}

An Acuson-128 XP echocardiograph (Acuson Co, Mountainview, California, USA) was used for the echocardiographic examination. A combined 2.0 and $2.5 \mathrm{MHz}$ transducer was used. The subjects were studied in the left lateral recumbent position. Echocardiographic techniques and calculations of different cardiac dimensions were performed in accordance with the recommendations of The American Society of Echocardiography Committee, ${ }^{21-23}$ using three consecutive expiratory beats. $M$ mode measurements of mitral ring motion were performed from four sites situated about $90^{\circ}$ apart, as described by Höglund et al. ${ }^{9}$ Recordings from the septal and lateral part of the mitral ring were obtained from the apical four chamber view and recordings from the posterior and anterior parts from the apical two chamber view. The leading edge technique was used and the amplitude of motion was measured from the nadir of the curve to the peak point, ${ }^{9}$ irrespective of positional changes during the isovolumic phases. The average of three beats was calculated for each site. The mitral ring motion was calculated as the average of the four sites.
In the reproducibility study the subjects were examined three times, first by BW, second by LB, and once again by BW. There was a pause for at least five minutes between the examinations, during which the subject could move and sit on the couch.

\section{RADIONUCLIDE ANGIOGRAPHY}

Radionuclide angiography was performed by equilibrium gated blood pool imaging. Red blood cells were labelled in vivo with $600 \mathrm{MBq}$ Tc $99 \mathrm{~m}$. Images were acquired with GE Camstar 2000 equipment (General Electric Medical Systems, Milwaukee, Wisconsin, USA) with patients in supine position. A parallel hole general purpose collimator was used. A $45^{\circ}$ left anterior oblique view with a $5^{\circ}$ cranio-caudal tilt was used. The angle was corrected for the best separation of the right and left ventricle. Seven hundred beats were recorded and each beat was divided into 24 frames. The ejection fraction was calculated from background corrected left ventricular counts versus time curve by standard commercial computer software (General Electric). The radionuclide angiography was undertaken within one hour after the echocardiographic examination.

In the reproducibility study two recordings were made with the patient in the same position, but with repositioning of the gamma camera. A third recording was obtained after a pause, during which the patient got up from the couch and sat in a chair for a minute.

STATISTICS

The Pearson correlation coefficient was used for analyses of linear correlation between different variables. The two tailed $t$ test was used to determine whether correlations were statistically significant.

The Bland and Altman method ${ }^{24}$ was used for assessing agreement between ejection fraction obtained by radionuclide angiography and that calculated by Teichholz's formula and Simpson's rule, respectively.

The paired two tailed $t$ test was used to determine whether differences between patients and age matched controls were significant and whether differences between calculations of ejection fraction by the echocardiographic methods and ejection fraction by radionuclide 

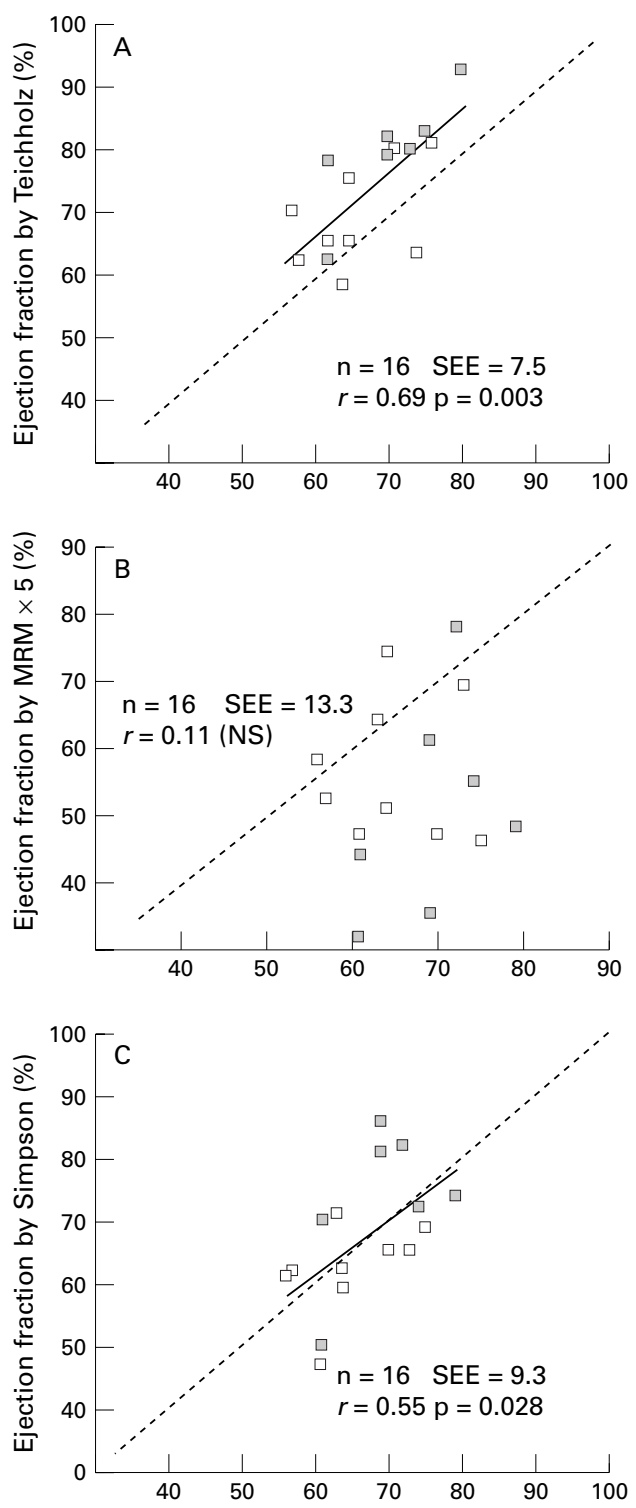

EF by radionuclide angiography (\%)

Figure 1 Correlation between ejection fraction $(E F)$ by radionuclide angiography and EF by Teichholz's formula $(A)$ and by mitral ring motion $(M R M) \times 5(B)$, and by Simpson's rule (C). Empty squares, patients with hypertension; shaded squares, patients with hypertrophic cardiomyopathy.

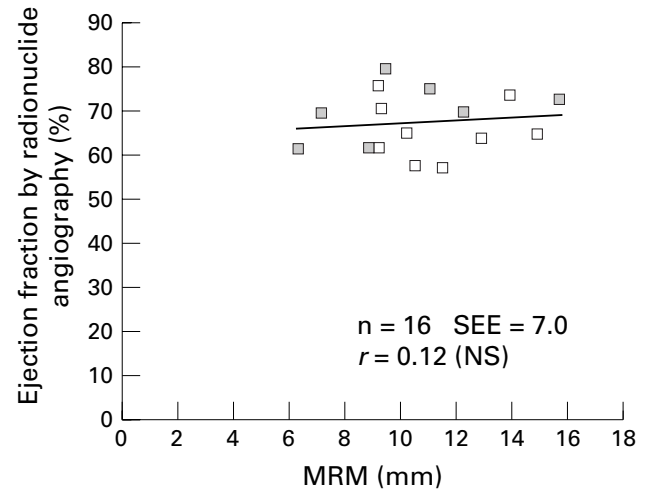

Figure 2 The correlation between mitral ring motion (MRM) and ejection fraction in patients with left ventricular hypertrophy. Empty squares, patients with hypertension; shaded squares, patients with hypertrophic cardiomyopathy.

angiography in the hypertrophy group were significant.

The 5\% level for significance was used.

The coefficient of variation, $\left[\mathrm{SD}_{\mathrm{x}-\mathrm{y}} /\right.$ mean $\mathrm{x}$, y] $\times 100$, was used to determine the reproducibility of the ejection fraction, obtained by radionuclide angiography.

\section{Results}

As seen in figs 1 and 2 the relation between the echocardiographic measurements and radionuclide ejection fraction did not differ between the two patient groups. Data were therefore pooled.

Echocardiographic measurements from the two $\mathrm{M}$ mode methods are detailed in table 2 . The group with left ventricular hypertrophy differed from the normal controls with respect to wall thickness $(p<0.001)$, heart rate $(p=0.006)$, mitral ring motion $(p<0.001)$, and the ratio of mitral ring motion to short axis diameter $(\mathrm{p}<0.001)$; there were no significant differences in the other measured variables.

The ejection fraction calculated by Teichholz's formula was $10.0 \%$ higher (+6.7 EF\%) than when measured by radionuclide angiography $(\mathrm{p}=0.002)$, and when calculated from mitral ring motion it was $19.3 \%$ lower $(-12.9$ $\mathrm{EF} \%)(\mathrm{p}=0.002)$. The mean value calculated by the Simpson's rule did not differ significantly from the value obtained by radionuclide angiography, but there was a considerable scatter

Table 2 Comparison of echocardiographic measurements and calculations between the hypertrophy group and healthy controls

\begin{tabular}{lrrrr}
\hline Variable & $\begin{array}{c}\text { Hypertrophy group } \\
(n=16)\end{array}$ & $\begin{array}{l}\text { Healthy controls } \\
(n=16)\end{array}$ & $\begin{array}{l}\text { Difference } \\
\text { in means }\end{array}$ & Significance \\
\hline Age (years) & $48.9(14.2)$ & $48.4(15.5)$ & 0.5 & $\mathrm{NS}$ \\
Height (cm) & $169.1(8.9)$ & $174.0(9.9)$ & -4.9 & $\mathrm{NS}$ \\
Weight (kg) & $75.9(11.2)$ & $75.6(9.3)$ & 0.6 & $\mathrm{NS}$ \\
Heart rate (beats/min) & $54.3(7.1)$ & $64.3(13.8)$ & -10.0 & $\mathrm{p}=0.006$ \\
Interventricular septum thickness (mm) & $21.1(7.7)$ & $10.7(1.0)$ & 10.4 & $\mathrm{p}<0.001$ \\
Left ventricular posterior wall thickness (mm) & $13.8(2.3)$ & $9.9(1.1)$ & 3.9 & $\mathrm{p}<0.001$ \\
Left ventricular end diastolic diameter (mm) & $47.6(8.1)$ & $50.2(4.6)$ & -2.6 & $\mathrm{NS}$ \\
Left ventricular end systolic diameter (mm) & $27.4(7.5)$ & $30.9(4.5)$ & -3.5 & $\mathrm{NS}$ \\
Systolic short axis diameter reduction (mm) & $20.3(3.8)$ & $19.3(2.4)$ & 1.0 & $\mathrm{NS}$ \\
Mitral ring motion (mm) & $10.8(2.6)$ & $15.2(1.3)$ & -4.4 & $\mathrm{p}<0.001$ \\
Ring motion at septal site (mm) & $10.5(2.6)$ & $14.3(1.8)$ & -3.8 & $\mathrm{p}<0.001$ \\
Ring motion at anterior site (mm) & $10.3(2.8)$ & $15.4(1.7)$ & -5.1 & $\mathrm{p}<0.001$ \\
Ring motion at lateral site (mm) & $11.3(2.8)$ & $15.6(2.0)$ & -4.3 & $\mathrm{p}<0.001$ \\
Ring motion at posterior site (mm) & $10.9(2.8)$ & $15.6(1.9)$ & -4.7 & $\mathrm{p}<0.001$ \\
Ejection fraction by Teichholz (\%) & $73.5(10.0)$ & $67.9(5.8)$ & 5.6 & $\mathrm{NS}(\mathrm{p}=0.077)$ \\
Ejection fraction by mitral ring motion $\times 5(\%)$ & $53.9(12.9)$ & $76.4(6.3)$ & -22.5 & $\mathrm{p}<0.001$ \\
Ratio mitral ring motion to short axis diameter change & $0.55(0.19)$ & $0.80(0.11)$ & -0.25 & $\mathrm{p}<0.001$ \\
\hline
\end{tabular}

Values are mean $(\mathrm{SD})$ 
Table 3 Comparison between ejection fraction (EF) obtained by radionuclide angiography and by three echocardiographic methods in the hypertrophy group $(n=16)$

\begin{tabular}{lllll}
\hline & $\begin{array}{l}\text { EF by radionuclide } \\
\text { angiography (\%) }\end{array}$ & $\begin{array}{l}\text { EF by Teichholz's } \\
\text { formula (\%) }\end{array}$ & $\begin{array}{l}\text { EF by mitral ring } \\
\text { motion } \times 5(\%)\end{array}$ & $\begin{array}{l}\text { EF by Simpson's } \\
\text { rule (\%) }\end{array}$ \\
\hline $\begin{array}{l}\text { Mean (SD) } \\
\begin{array}{l}\text { Difference from EF by } \\
\quad \text { radionuclide angiography }\end{array}\end{array}$ & $66.8(6.8)$ & $73.5(10.0)$ & $53.9(12.9)$ & $67.3(10.7)$ \\
$\begin{array}{l}\text { Level of significance of difference } \\
\text { Correlation to EF by radionuclide } \\
\quad \text { angiography }\end{array}$ & - & $+6.7(7.3)$ & $-12.9(13.9)$ & $+0.5(9.0)$ \\
$\begin{array}{l}\text { Level of significance of correlation } \\
\text { Limits of agreement }\end{array} \quad-$ & $\mathrm{p}=0.002$ & $\mathrm{p}=0.002$ & $\mathrm{NS}$ \\
$\quad($ mean difference $\pm 2 \mathrm{SD})$ & - & $r=0.69$ & $r=0.11$ & $r=0.55$ \\
& $\mathrm{p}=0.003$ & $\mathrm{NS}$ & $\mathrm{p}=0.028$ \\
\end{tabular}
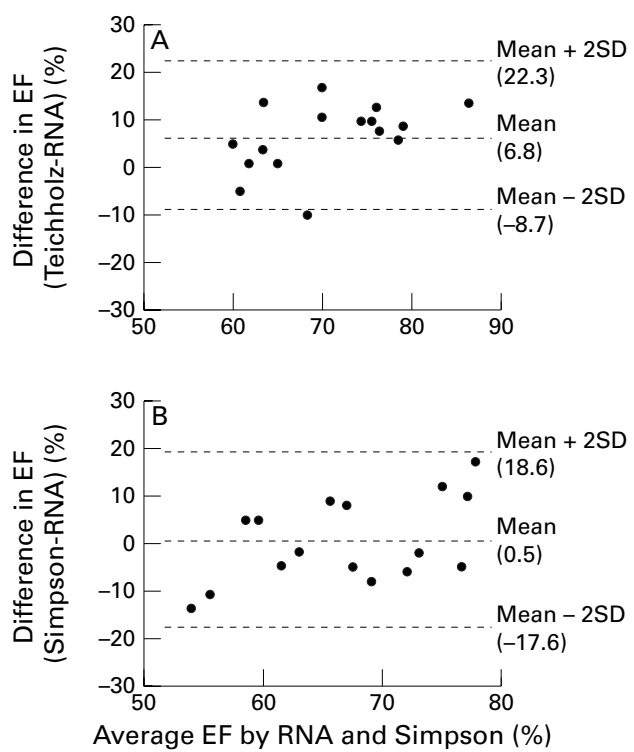

Figure 3 Bland and Altman diagrams showing difference against mean for ejection fraction $(E F)$ calculated by Teichholz's formula (A) and by Simpson's rule (B), compared with values obtained by radionuclide angiography (RNA).

Table 4 Correlation between some measured and calculated variables and the degree of overestimation of ejection fraction $(E F)$ by Teichholz's formula $(n=16)$

\begin{tabular}{|c|c|c|}
\hline & $\begin{array}{l}\text { Linear correlation to } \\
\text { overestimation of } E F\end{array}$ & $\begin{array}{l}\text { Level of } \\
\text { significance }\end{array}$ \\
\hline Wall thickness & $r=0.62$ & $p=0.011$ \\
\hline LV end systolic diameter & $r=-0.47$ & NS \\
\hline $\begin{array}{l}\text { Hypertension or } \\
\text { cardiomyopathy }\end{array}$ & $r=0.44$ & NS \\
\hline Age & $r=-0.31$ & NS \\
\hline $\begin{array}{l}\text { LV end diastolic diameter } \\
\text { EF by radionuclide }\end{array}$ & $r=-0.16$ & NS \\
\hline angiography & $r=0.13$ & NS \\
\hline Sex & $r=0.05$ & NS \\
\hline
\end{tabular}

about the regression line with standard error of the estimate ( $=$ standard deviation of the residuals) of 9.3 (EF\%) (fig 1; table 3 ).

There was no significant correlation between mitral ring motion or ejection fraction estimated by MRM $\times 5$, and values obtained by radionuclide angiography (figs 1,2 ) (table 3 ).

Bland and Altman analysis was undertaken for calculation of ejection fraction by Teichholz's formula and by Simpson's rule, compared with values obtained by radionuclide angiography. The limits of agreement (= mean difference \pm 2 SD) was -8.7 and $22.3 \mathrm{EF} \%$ for Teichholz's formula and -17.6 and $18.6 \mathrm{EF} \%$ for Simpson's rule (fig 3; table 3).

The degree of overestimation of the ejection fraction by Teichholz's formula correlated significantly with wall thickness $(r=0.62)$ (table 4).

There was no significant correlation between the degree of underestimation of ejection fraction by $M R M \times 5$ and the tested variables: wall thickness, left ventricular end diastolic diameter or end systolic diameter, systolic short axis diameter shortening, clinical diagnosis (cardiomyopathy or hypertension), sex, or age.

The study showed the excellent reproducibility of radionuclide angiography, with a coefficient of variation (cv) of $1.7 \%$ with repositioning of the gamma camera between the recordings and $2.7 \%$ when the patient also sat in a chair between the recordings. Intraindividual and interindividual reproducibility was also very good for measurements of mitral ring motion in young healthy subjects, with cv values of $2.4 \%$ and $3.5 \%$, respectively. The reproducibility was slightly lower for Teichholz's formula (cv 5.1\% for intraindividual and $5.6 \%$ for interindividual reproducibility) and for Simpson's rule $(4.9 \%$ for intraindividual

Table 5 Reproducibility of ejection fraction (EF) obtained by radionuclide angiography and calculated by the echocardiograhic methods in 10 consecutive patients with left ventricular hypertrophy, and the reproducibility for the echocardiographic methods in 10 healthy young subjects examined by the same investigators and the same equipment

\begin{tabular}{|c|c|c|c|c|}
\hline & $\begin{array}{l}\text { EF by radionuclide } \\
\text { angiography }\end{array}$ & $\begin{array}{l}\text { EF by Teichholz's } \\
\text { formula }\end{array}$ & $\begin{array}{l}\text { EF by mitral ring } \\
\text { motion } \times 5\end{array}$ & $\begin{array}{l}\text { EF by Simpson's } \\
\text { rule }\end{array}$ \\
\hline $\begin{array}{l}\text { Repositioning of the gamma camera } \\
\text { between the recordings }\end{array}$ & $\mathrm{cv}=1.7 \%$ & - & - & - \\
\hline $\begin{array}{l}\text { When the patient also sat in a chair } \\
\text { between the recordings }\end{array}$ & $\mathrm{cv}=2.7 \%$ & - & - & - \\
\hline $\begin{array}{l}\text { Intraindividual reproducibility in young } \\
\text { healthy subjects }\end{array}$ & - & $\mathrm{cv}=5.1 \%$ & $\mathrm{cv}=2.4 \%$ & $\mathrm{cv}=4.9 \%$ \\
\hline $\begin{array}{l}\text { Interindividual reproducibility in young } \\
\text { healthy subjects }\end{array}$ & - & $\mathrm{cv}=5.6 \%$ & $\mathrm{cv}=3.5 \%$ & $\mathrm{cv}=6.8 \%$ \\
\hline $\begin{array}{l}\text { Intraindividual reproducibility in patients } \\
\text { with left ventricular hypertrophy } \\
\text { Interindividual reproducibility in patients }\end{array}$ & - & $\mathrm{cv}=14.9 \%$ & $\mathrm{cv}=20.1 \%$ & $\mathrm{cv}=18.1 \%$ \\
\hline with left ventricular hypertrophy & - & $\mathrm{cv}=18.4 \%$ & $\mathrm{cv}=26.2 \%$ & $\mathrm{cv}=28.1 \%$ \\
\hline
\end{tabular}

Coefficient of variation $(\mathrm{cv})=\mathrm{SD}$ of difference/mean value $\times 100$. 


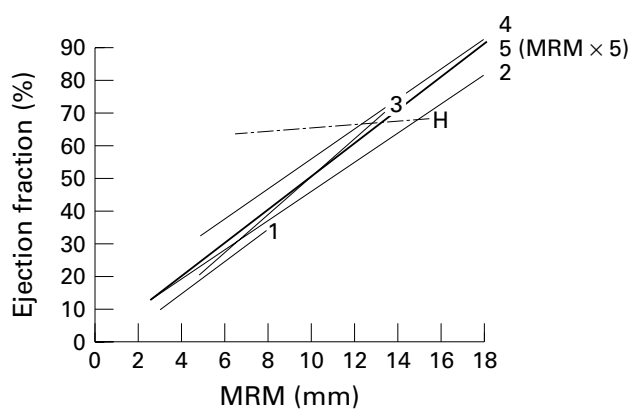

Figure 4 The correlation between mitral ring motion $(M R M)$ and ejection fraction (EF\%) in four previous studies, in patients with hypertrophy in the present study, and $E F \%=M R M(m m) \times 5$. (1) Alam, $1990^{11}: E F$ $(\%)=5.0 \times M R M(m m)-5.6 ; r=0.82 ;$ (2) Pai, $1991^{19}: E F(\%)=4.4 \times M R M(m m)+1.5 ; r=0.95 ;$ (3) Alam, $1991^{18}: E F(\%)=5.5 \times M R M(\mathrm{~mm})-5$ $r=0.87 ;$ (4) Alam, $1992^{17}: E F(\%)=4.4 \times M R M(\mathrm{~mm})$ $+11.5 ; r=0.89 ;(5) E F(\%)=5 \times M R M(m m) ; H$, patients with left ventricular hypertrophy $(r=0.12, \mathrm{NS})$.

and $6.8 \%$ for interindividual reproducibility). In the patients, all three echocardiographic methods had a considerably lower reproducibility, with a cv over $14 \%$ for intraindividual reproducibility and over $18 \%$ for interindividual reproducibility, with the lowest reproducibility for Simpson's rule (table 5).

\section{Discussion}

Left ventricular ejection fraction is a commonly used index of systolic function and can be obtained by contrast cineangiography, radionuclide angiography, and cross sectional and $\mathrm{M}$ mode echocardiographic methods. Radionuclide angiography is regarded as the gold standard because it does not require geometric assumptions and was used as the reference method in this investigation. Echocardiographic methods are widely used, having the advantages of being non-invasive, reasonable cheap, and not involving radiation.

Of the echocardiographic methods, Simpson's rule is the most commonly used. However, as stressed in a recent report from Naik and co-workers, ${ }^{25}$ even though there is a high correlation between determination by cross sectional echocardiography and the reference methods, there is only a moderate agreement. Using the method of Bland and Altman in a prospective study and in a retrospective analysis of seven previous studies identified by a MEDLINE computer search, they
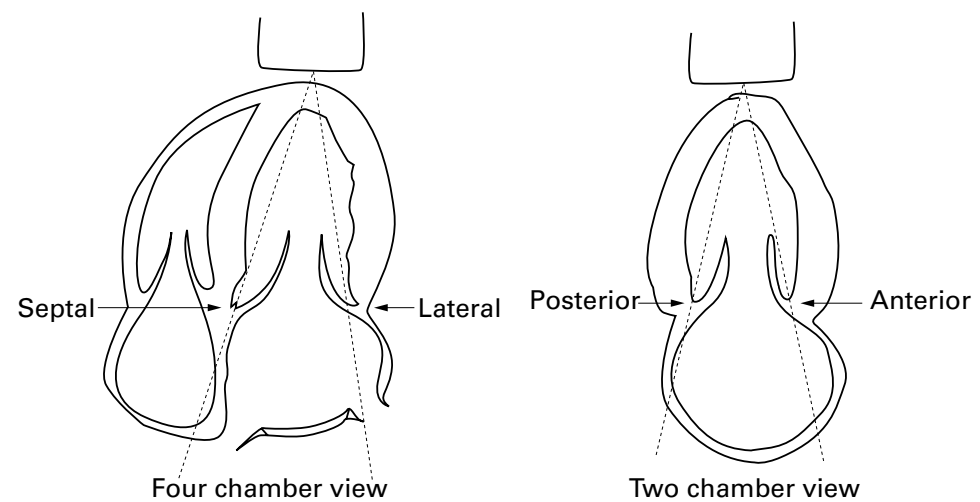

Figure 5 Schematic illustration of the four sites of the mitral ring where measurements are obtained for calculation of mitral ring motion. found an average lack of agreement $(=2 \mathrm{SD}$ of the difference) between ejection fraction calculated from two dimensional echocardiography and the reference method of $17 \mathrm{EF} \%$. The lack of agreement between the Simpson's rule and radionuclide angiography in the present study was $18.1 \mathrm{EF} \%$, with limits of agreement (= mean difference \pm 2 SD) of -17.6 and 18.6. These figures show that there is only a moderate agreement also in patients with left ventricular hypertrophy.

The Teichholz formula, ${ }^{16}$ based on short axis measurements of the left ventricular inner diameter, is the most commonly used $\mathrm{M}$ mode method. Calculations of the ejection fraction by this formula are performed by all modern echocardiographs. Estimation of ejection fraction from echocardiographic measurements of the mitral ring motion in the long axis of the heart is quite a new method which has quickly gained ground during recent years. ${ }^{811}{ }^{17-19}$ The Teichholz formula has shown a high correlation with ejection fraction, obtained from reference methods, in cases without regional wall motion abnormalities. ${ }^{16}$ Estimations from mitral ring motion have shown high correlations with values from reference methods even when cases with regional wall motion abnormalities were included ${ }^{11}{ }^{18}$ (fig 4).

The results in our present study show that there is a significant relation between ejection fraction calculated from the Teichholz formula and that determined by radionuclide angiography, but that the ejection fraction calculated from Teichholz's formula is significantly higher than that measured by radionuclide angiography. In contrast, there was no significant relation between mitral ring motion and ejection fraction in patients with left ventricular hypertrophy, irrespective of whether this was caused by hypertension or was a feature of cardiomyopathy (figs 1 and 2).

The recording of mitral ring motion is a new but rapidly spreading method of assessing left ventricular function. Studies have shown that $M$ mode measurements from four aspects of the mitral ring, as described by Höglund and co-workers $^{9}$ (fig 5), are highly reproducible. ${ }^{9} 1317$ The recordings can be obtained from the vast majority of patients ${ }^{26}$ and are not limited by the need for accurate endocardial border identification. However, as the method is rather new its limitations may not yet be fully apparent. In addition to underestimating left ventricular function in patients with hypertrophy, as concluded in the present study, several other limitations are likely to be reported during the next few years. Furthermore, adequate reference values must be used when mitral ring motion is employed for assessing left ventricular function. In a recent study, reference values for a wide range of body size and age were reported. ${ }^{20}$

Even though several studies have shown strong correlation between mitral ring motion and ejection fraction (fig 4), it is questionable if it is wise to translate ring motion to ejection fraction. If ring motion is employed for estimating ejection fraction, different conversion factors should be used that take age into account, ${ }^{27}$ as ejection fraction at rest is 
unchanged or slightly increased with advancing age $^{28-30}$ while mitral ring motion is decreased. ${ }^{2027}$

Mitral ring motion has also been used to assess left ventricular function without investigating the ejection fraction. ${ }^{26} 3132$ The most proper way to use this technique is probably to use the measures as such, with adequate reference values, ${ }^{20}$ and not by artificially creating an ejection fraction.

In our present study the amplitude of mitral ring motion was measured from the nadir to the peak excursion, irrespective of positional changes during the isovolumic phases, as described by Höglund, ${ }^{9}$ and as applied in previous studies. ${ }^{11}{ }^{17}{ }^{18}$ In most healthy subjects the peak point occurs in the end systole. In a few subjects the ring motion continues a short distance towards the apex during the isovolumic relaxation phase. ${ }^{27}$ In many patients with left ventricular hypertrophy the ring moves a considerable distance towards the apex during the isovolumic relaxation phase. The peak excursion occurred in the isovolumic relaxation phase in eight of the 16 patients in the present study. That means that the underestimation of ejection fraction would have been even more pronounced if we had made the measurements during the end systolic period in all patients. Generally, however, when mitral ring motion is used for assessing left ventricular function, measurement should probably be made at the time of aortic valve closure. Significant differences between this and the maximum downward motion could probably be used to indicate increased (abnormal) shape changes in the isovolumic period. The interpretation of such changes, however, remains to be investigated.

Recordings of mitral ring motion contain a lot more information than the total amplitude of motion (fig 6). The atrial contribution to the total motion ${ }^{33} 34$ and the maximum diastolic longitudinal relaxation velocity, represented by the maximum inclination on the curve,${ }^{35}$ have been suggested as means to assess left ventricular diastolic function.

Recently Doppler tissue imaging from the mitral ring motion has been reported to be a useful method for assessment of left ventricular systolic $^{36}$ and diastolic function. ${ }^{37}$ This technique shows the velocity of the ring motion during the different parts of the heart cycle,

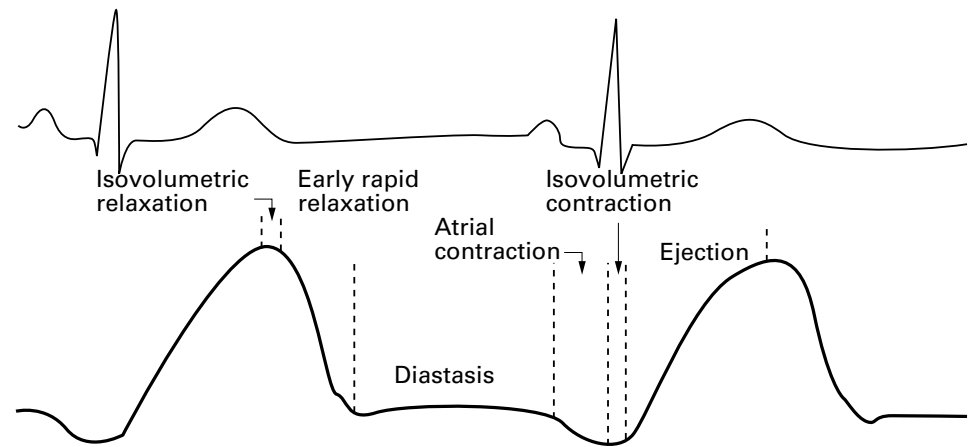

Figure 6 Schematic figure of the different parts of $M$ mode recording of mitral ring motion. which is equivalent to the first derivative of the $M$ mode measures.

The reproducibility study showed significantly lower reproducibility in patients with left ventricular hypertrophy than in young healthy subjects, for all three echocardiographic methods (table 5). This may also be the case in other patient groups, and the results point to the need to report reproducibility for the actual patient group investigated.

In hypertrophy caused by hypertension, as in hypertrophic cardiomyopathy, there is an increase in mean muscle cell diameter, but there are more pronounced alterations in hypertrophic cardiomyopathy, with areas with marked fibre disarray and disorganisation of the intercellular junctions. ${ }^{38}{ }^{39}$ There are also larger areas with fibrosis in hypertrophic cardiomyopathy than in hypertension. ${ }^{40} \mathrm{De}-$ spite these differences at the microscopic level, there were no obvious differences in the relations between the echocardiographic measurements and ejection fraction between patients with hypertrophic cardiomyopathy and those with hypertension in this study (figs 1 and 2).

This paper specifically deals with calculation of ejection fraction in left ventricular hypertrophy, and with the shortcomings of the echocardiographic methods in these patients. However, it is important to stress the limitations of using the ejection fraction as a measure of left ventricular systolic function in hypertrophy. Compared with normal subjects, many patients with hypertrophy and preserved short axis shortening, measured from the endocardium, not only have reduced long axis shortening also reduced circumferential shortening, measured from the mid-wall, indicating suppressed myocardial function. ${ }^{12}{ }^{41}$ However, the reason for depressed long axis contraction in left ventricular hypertrophy remains to be investigated. In the present study there was no significant correlation between the wall thickness and the ratio of mitral ring motion to short axis diameter shortening. This suggests that simple geometric alterations owing to the increased wall thickness cannot explain the decreased long axis contractions.

\section{LIMITATIONS}

There was not a clinical indication for radionuclide angiography in any of the patients. Therefore the number of patients had to be limited according to the rules of the local ethics and isotope committees. As seen in figs 1 and 2 there was no obvious difference between the two patients groups concerning the relation between the echocardiographic measurements and radionuclide ejection fraction, but because of the small number of patients in each group we cannot rule out the possibility that a larger number of patients might have revealed some differences between the groups.

As well as investigating the relation between ejection fraction by the different echocardiographic methods and true ejection fraction in patients with left ventricular hypertrophy, it would had been of great interest to investigate the calculated volumes of the left ventricle and 
the true volumes. This could not be done because radionuclide angiography, which is regarded as gold standard in the study, only gives the relative volume changes during the heart cycle, and not the absolute volumes. Calculations by Simpson's rule cannot be regarded as true volumes in these patients. Papillary muscle mass is normally disregarded in patients with normal or dilated hearts, but this may become a significant error when the muscle is hypertrophied, especially if the end systolic volume is small.

CONCLUSIONS

This echocardiographic study showed that in patients with left ventricular hypertrophy the ejection fraction calculated by Teichholz's formula or Simpson's rule is a poor measure of left ventricular function, and that when mitral ring motion is used for the assessment in these patients the function should be expressed in ways other than ejection fraction.

We gratefully acknowledge Ms Kerstin Ling for her assistance in the preparation of this manuscript, and Mr Ingemar Adolfsson for his statistical advice. Supported in part by the Swedish Medical Research Council grant 9481 and the Swedish Heart Lung Foundation.

$1 \mathrm{McD}$ onald IG. The shape and movement of the human left ventricle during systole. A study by cineangiography and by 1970;26:221-30

2 Rushmer RF. Cardiovascular dynamics. Philadelphia: WB Saunders, 1976:63.

3 Lundbäck S. Cardiac pumping and function of the left ventricular septum. Acta Physiol Scand Suppl 1986;550:1-101.

4 Slager CJ, Hooghoudt TEH, Serruys PW, et al. Quantitative assessment of regional left ventricular motion using

5 Holmgren BS. The movement of the mitro-aortic ring recorded simultaneously by cine-roentgenography and electrocardiography. Acta Radiol 1946;27:171-6.

6 Odqvist $H$. A roentgen cinematographic study of the movement of the mitral ring during heart action. Acta Radio 1945;26:392-6.

7 Zaky A, Grabhorn L, Feigenbaum H. Movement of the mitral ring: a study in ultrasound cardiography. Cardiovasc Res 1967;1:121-31.

8 Simonson JS, Schiller NB. Descent of the base of the left ventricle: an echocardiographic index of the left ventricle. $\mathcal{F}$ Am Soc Echocardiogr 1988;2:25-35.

9 Höglund C, Alam M, Thorstrand C. Atrioventricular plane displacement in healthy persons. An echocardiographic study. Acta Med Scand 1988;224:557-62.

10 Assman PE, Slager CJ, Dreysse ST, et al. Two-dimensional echocardiographic analysis of the dynamic geometry of the echocardiographic analysis of the dynamic geometry of the motion. . Am Soc Echocardiogr 1988;1:393-405.

11 Alam M, Höglund C, Thorstrand C, et al. Atrioventricular plane displacement in severe congestive heart failure following dilated cardiomyopathy or myocardial infarction. f Intern Med 1990;228:569-75.

12 Jones CJH, Raposo L, Gibson DG. Functional importance of long axis dynamics of the human left ventricle. Br Hear f 1990;63:215-20.

13 Hammarström E, Wranne B, Pinto FJ, et al. Tricuspid annular motion. F Am Soc Echocardiogr 1991;4:331-9.

14 Hoffman EA, Ritman EL. Invariant total heart volume in the intact thorax. Am f Physiol 1985;249:883-90.

15 Wigström L, Lindström L, Sjöqvist L, et al. M-mode magnetic resonance imaging: a new modality for assessing cardiac function. Clin Physiol 1995;4:397-407.

16 Teichholz LE, Kreulen T, Herman MV, et al. Problems in echocardiographic volume determinations: echocardiographic angiographic correlations in the presence or graphic angiographic correlations in the prese

17 Alam M, Höglund C, Thorstrand C, et al. Haemodynamic significance of the atrioventricular plane displacement in patients with coronary artery disease. Eur Heart F 1992;13: 194-200.

18 Alam $M$. The atrioventricular plane displacement as a means to evaluate left ventricular function in acute myocardial infarction. Clin Cardiol 1991;41:588-94.

19 Pai RG, Bodenheimer MM, Pai SM, et al. Usefulness of systolic excursion of the mitral annulus as an index of left ventricular systolic function. Am f Cardiol 1991;67:222-4.

20 Wandt B, Bojö L, Wranne B. Influence of body size and age on mitral ring motion. Clin Physiol 1997;17:635-46.

21 Sahn DJ, De Maria A, Kisslo J, et al. Recommendations regarding quantitation in M-mode echocardiography. Results of a survey of echocardiographic measurements. Circulation 1978;58:1072-83.

22 Henry WL, De Maria A, Gramiak R, et al. Report of the American Society of Echocardiography Committee on nomenclature and standards in 2-D echocardiography. Circulation 1980;62:212-17.

23 Schiller NB, Shah PM, Crawford M, et al. Recommendations for quantitation of the left ventricle by twodimensional echocardiography. $7 \mathrm{Am}$ Soc Echocardiogr 1989;5:358-67.

24 Bland JM, Altman DG. Statistical methods for assessing agreement between two methods of clinical measurement. Lancet 1986;i:307-10.

25 Naik MM, Daimond GA, Soffer A, et al. Correspondence of left ventricular ejection fraction determination from two dimensional echocardiography, radionuclide angiography and contrast cineangiography. F Am Coll Cardiol 1995;25: 937-42.

26 Willenheimer R, Cline C, Erhardt L, et al. Left ventricular atrioventricular plane displacement: an echocardiographic technique for rapid assessment of prognosis in heart technique for rapid assessmen
failure. Heart 1997;78:230-6.

27 Wandt B, Bojö L, Hatle L, et al. Left ventricular contraction pattern changes with age in normal adults. F $\mathrm{Am}$ Soc Echocardiogr 1998;11:857-63.

28 Port S, Cobb FR, Coleman E, et al. Effect of age on the response of the left ventricular ejection fraction to exercise. N Engl F Med 1980;303:1133-7.

29 Pfisterer ME, Battler A, Zaret BL. Range of normal values for left and right ventricular ejection fraction at rest and during exercise assessed by radionuclide angiography. Eur Heart f 1985;6:647-55.

30 Bauer R, Busch U, van der Flierdt E, et al. Altersabhängigkeit der Herzfuntion bei Herzgesunden. $Z$ Kardiol 1988;77: $632-41$.

31 Keren G, Sonnenblick E, Le Jemtel TH. Mitral annulus motion: relation to pulmonary venous and transmitral flows in normal subjects and in patients with dilated cardiomyopathy. Circulation 1988;78:621-9.

32 Höglund C, Alam M, Thorstrand C. Effects of acute myocardial infarction on the displacement of the atrioventricular plane: an echocardiographic study. 7 Intern Med 1989;226:251-6.

33 Alam M, Höglund C. Assessment by echocardiogram of left ventricular diastolic function in healthy subjects using the atrioventricular plane displacement. Am f Cardiol 1992:69: $565-8$.

34 Blomstrand P, Kongstad O, Broqvist M, et al. Assessment of left ventricular diastolic function from mitral annular motion, a comparison with pulsed Doppler measurements in patients with heart failure. Clin Physiol 1996;16:483-93.

35 Bojö L, Wandt B, Ahlin NG. Reduced left ventricular relaxation velocity after acute myocardial infarction. Clin Physiol 1998;3:195-201.

36 Gualati VK, Katz WE, Follansbee WP, et al. Mitral annular descent velocity by tissue Doppler echocardiography as an index of global left ventricular function. $\mathrm{Am}$ f Cardiol 1996;77:979-84.

37 Lindström L, Wranne B. Pulsed tissue Doppler evaluation of mitral annulus motion: a new window to assessment of diastolic function. Clin Physiol 1999;19:1-10.

38 Hoshino T, Fujiwara H, Kawai C, et al. Myocardial fiber diameter and regional distribution in the ventricular wall of normal adult hearts, hypertensive hearts and hearts with hypertrophic cardiomyopathy. Circulation 1983;67:110916

39 Sepp R, Severs NJ, Gourdie RG. Altered patterns of cardiac intracellular junction distributed in hypertrophic cardiomyopathy. Heart 1996;76:412-17.

40 Tanaka M, Fujiwara H, Onodera $\mathrm{T}$, et al. Quantitative analysis of myocardial fibrosis in normals, hypertensive hearts, and hypertrophic cardiomyopathy. Br Heart $\mathcal{F} 1986$; 55:575-81.

41 Aurigemma GP, Silver KH, Priest MA, et al. Geometric changes allow normal ejection fraction despite depressed myocardial shortening in hypertensive left ventricular hypertrophy. $f$ Am Coll Cardiol 1995;26:195-202. 